\title{
Developing a causal model of game addiction and stealing behavior among undergraduate students
}

\author{
Thitiwat Numkhan \& Waiphot Kulachai \\ Burapha University, Chonburi, Thailand
}

\begin{abstract}
The objectives of this study were to examine game addiction and stealing behavior, factors affecting game addiction, and factors affecting stealing behavior among undergraduate students. The samples of this study were 340 undergraduate students from 3 universities, Burapha University, Rajamangala University of Technology Tawan-ok, and Kasetsart University Sriracha Campus. The questionnaire was employed to collect the data. The collected data were analyzed using structural equation modeling technique. The results indicated that game addiction had a positive effect on stealing behavior. The most important factor affecting game addiction was friend influence followed by family relationship, and social environment respectively. Then, discussion and implication for related stakeholders were discussed.
\end{abstract}

Keywords: stealing behavior, affecting game addiction, family relationship, social environment

\section{INTRODUCTION}

Games nowadays play important role on young people daily lives. Using internet to access playing online games is quite normal today since personal computer and internet have been introduced. This results in game addiction problem. Some of young people has addicted to game and do not pay attention on their study leading to poor academic performance (Kiatpojananan 2010). There are various factors affecting game addiction among young people which are biological, psychological, social, and family factors (Charoenwanich 2014). Chutchawarut (2009) explained that there are five main factors affecting game addiction; personal factor, nurturing, friend influence, social environment, and changing in brain's chemical substances. A research conducted by Kolkijkovin et al. (2009) found that relationship in the family also an antecedence of game addiction. Hence, the hypotheses were proposed as followings;

H1: Family relationship has positive effect on game addiction

$\mathrm{H} 2$ : Friend influence has positive effect on game addiction

H3: Social environment has positive effect on game addiction

Addiction to both online and offline game results in psychological consequences. Addicted people may perform aggressive behavior, cannot control themselves, obtain money by illegal means, and have poor relationship with their family members
(Kulsiripunyo 2015). She also found that addiction to game leads to stealing behavior. Therefore, the fourth hypothesis was proposed.

H4: Game addiction has positive effect on stealing behavior

As game addiction has become a serious problem among teenagers and undergraduate students, we would like to examine the factors leading to game addiction. Also, some undergraduate students try to obtain money in illegal way to pay for the game. We also would like to find out the linkage between game addiction and stealing behavior in this research. Discussion about the results and implication will be discussed in the latter part of this article.

\section{RESEARCH METHOD}

\subsection{Sample}

The samples of this study were 340 undergraduate students from 3 universities, Burapha University, Rajamangala University of Technology Tawan-ok, and Kasetsart University Sriracha Campus. The majority of them were female (56.5\%). About $39.5 \%$ of the samples were at the age of 19 years old. The second year students were the majority accounting for $34.1 \%$. Most of them got financial support from their parents around 6,001 - 9,000 Baht a month. More than $79 \%$ of the respondents lived with friends or alone. They played game 1-2 days a week (38.8\%). 
Many of them played game in order to relief stress $(58.8 \%)$.

\subsection{Measures}

There were five measures in this study which were family relationship (FA), friend influence (FIN), social environment, game addiction, and stealing behavior.

Family relationship was the 5-point Likert's scale anchored by (1) strongly disagree and (5) strongly agree. It had 4 items such as "I always have a problem with my parents," "My parents do not take a good care of me," and "My parents do not understand my need and desire." This measure provided the Cronbach's alpha of 0.925 .

Friend influence was the 5-point Likert's scale anchored by (1) strongly disagree and (5) strongly agree. It had 4 items such as "I always go to play game every time when my friend asks me," "I get many new friends from playing game," and "Playing game with friend gives me a lot of fun." This measure provided the Cronbach's alpha of 0.930.

Social environment was the 5-point Likert's scale anchored by (1) strongly disagree and (5) strongly agree. It had 3 items such as "The internet café is close to my residence and very convenient to get there," "The internet café nearby my place opens 24 hours," and "It is easy to access to the internet café." This measure provided the Cronbach's alpha of 0.931 .

Game addiction was the 5-point Likert's scale anchored by (1) strongly disagree and (5) strongly agree. It had 3 items such as "I always upset when someone asks me to stop playing game," "I always talk about games," and "Playing games is my major hobby." This measure provided the Cronbach's alpha of 0.859 .

Stealing behavior was the 5-point Likert's scale anchored by (1) strongly disagree and (5) strongly agree. It had 3 items such as "I always steal my parents' money," "I always steal others' money," and "I always take someone's belongings whenever there is no one there." This measure provided the Cronbach's alpha of 0.838 .

\subsection{Analysis}

Descriptive statistics such as mean, frequency, percentage, standard deviation were used to explain the attributes of each variable. The validity of the measurement models was tested using confirmatory factor analysis (CFA). The authors also employed structural equation modeling technique to analyze the collected data.

\section{RESULTS}

\subsection{Confirmatory factor analysis}

In this study, the confirmatory factor analysis (CFA) was employed to test the validity of each measurement model. The results of this analysis are as illustrated in Figure 1 and Table 1.

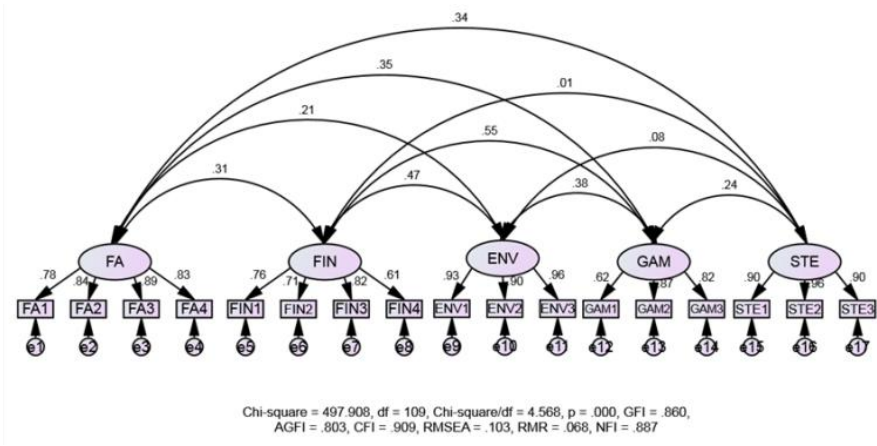

Figure 1. Standardized path estimates for the hypothesized CFA model

Table 1. CFA results (hypothesized model)

\begin{tabular}{lll}
\hline \multicolumn{1}{c}{ Goodness of fit index } & \multicolumn{1}{c}{$\begin{array}{c}\text { Acceptable } \\
\text { Value }\end{array}$} & Results \\
\hline Chi-square & Sig. is expected & $p=.000$ \\
\hline Absolute fit measures & & \\
GFI & $>0.90$ & 0.860 \\
RMSEA & $<0.07$ & 0.103 \\
RMR & Low & 0.068 \\
Normed Chi-square & $2-5$ & 4.568 \\
\hline Incremental fit indices & & \\
NFI & Approach to 1 & 0.887 \\
CFI & $>0.92$ & 0.909 \\
RFI & Approach to 1 & 0.860 \\
\hline Parsimony fit indices & \multicolumn{2}{|}{} \\
AGFI & Approach to 1 & 0.803 \\
PNFI & Approach to 1 & 0.711 \\
\hline
\end{tabular}

Figure 1 and Table 1 shows the overall model chisquare of 497.808 with 109 degree of freedom. The $p$-value associated with the result is 0.000 . This could be implied that the chi-square goodness of fit statistic does not indicate that the observed covariance matrix matches the estimated covariance matrix within sampling variance. The value of RMSEA is 0.103 . This value indicates additional support for model fit. The normed Chi-square is 4.568 is considered acceptable fit for the CFA model. Ac-cording to the incremental fit indices, the CFI has a value of 0.909 which lower than the suggested cutoff values. In addition, the AGFI has the value of 0.803 which reflects poor model fit.

The authors allowed the error of estimation to covariance in accordance with the modification indices. The CFA model was then reestimated. The results of the analysis are as shown in Figure 2 and Table 2. 


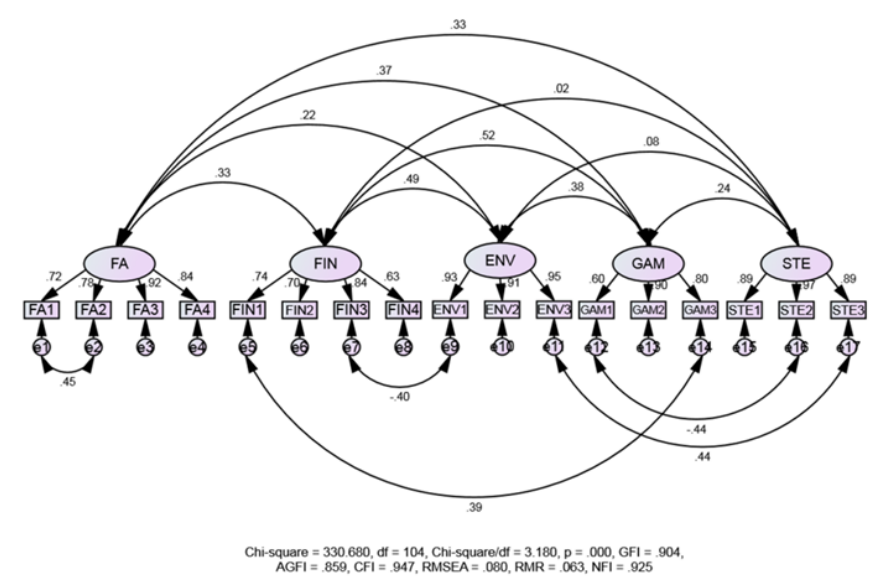

Figure 2. Standardized path estimates for the revised CFA Model

Table 2. CFA results (revised model)

\begin{tabular}{lll}
\hline \multicolumn{1}{c}{ Goodness of fit index } & $\begin{array}{c}\text { Hypothesized } \\
\text { model }\end{array}$ & $\begin{array}{c}\text { Revised } \\
\text { Model }\end{array}$ \\
\hline Chi-square & $p=0.000$ & $p=0.000$ \\
\hline Absolute fit measures & & \\
GFI & 0.860 & 0.904 \\
RMSEA & 0.103 & 0.080 \\
RMR & 0.068 & 0.063 \\
Normed Chi-square & 4.568 & 3.180 \\
\hline Incremental fit indices & & \\
NFI & 0.887 & 0.925 \\
CFI & 0.909 & 0.947 \\
RFI & 0.860 & 0.902 \\
\hline Parsimony fit indices & & \\
AGFI & 0.803 & 0.859 \\
PNFI & 0.711 & 0.708 \\
\hline
\end{tabular}

The results illustrate the overall fit statistics from testing the revised model. The chi-square is 330.680 with 104 degree of freedom $(\mathrm{p}<.05)$, and the normed chi-square is 3.180 . The model CFI is .947 with RMSEA of 0.080 . All of these measures are within an acceptable range. These suggest that the model provides overall good fit.

The convergent validity and construct validity were examinined as illustrated in Table 3.

Table 3. Standardized factor loadings, average variance extracted, and reliability estimated

\begin{tabular}{|c|c|c|c|c|c|}
\hline & FA & FIN & ENV & GAM & STE \\
\hline FA1 & 0.719 & & & & \\
\hline FA2 & 0.784 & & & & \\
\hline FA3 & 0.924 & & & & \\
\hline FA4 & 0.843 & & & & \\
\hline FIN1 & & 0.737 & & & \\
\hline FIN2 & & 0.703 & & & \\
\hline FIN3 & & 0.840 & & & \\
\hline FIN4 & & 0.627 & & & \\
\hline
\end{tabular}

Table 3, cont.

\begin{tabular}{|c|c|c|c|c|c|}
\hline ENV1 & & & 0.927 & & \\
\hline ENV2 & & & 0.911 & & \\
\hline ENV3 & & & .953 & & \\
\hline GAM1 & & & & 0.599 & \\
\hline GAM2 & & & & 0.900 & \\
\hline GAM3 & & & & 0.799 & \\
\hline STE1 & & & & 0.894 & \\
\hline STE2 & & & & 0.970 & \\
\hline STE3 & & & & 0.891 & \\
\hline $\begin{array}{l}\text { Average vari- } \\
\text { ance extracted } \\
(\%)\end{array}$ & 67.40 & 53.40 & 86.58 & 60.24 & 84.46 \\
\hline $\begin{array}{l}\text { Construct relia- } \\
\text { bility }\end{array}$ & 0.985 & 0.960 & 0.992 & 0.980 & 0.990 \\
\hline
\end{tabular}

Table 3 displays the standardized factor loadings. The lowest loading obtained is .599 linking game addiction (GAM) to item GAM1. Only two other lodaing estimate fall just below the .70 standard. The average variance extracted estimates and the construct reliabilities are shown in the bottom of the table. The AVE estimates range from $53.40 \%$ for friend influence (FIN) to $86.58 \%$ for social environment (ENV). All exceed $50 \%$ rule of thumb. The construct reliabilites range from 0.960 for the FIN construct to .992 for the ENV construct. These exceed 0.70 indicating adwquate reliability.

\subsection{Structural equation modeling}

The objective of this analysis is to examine the relationships between each latent variable. The results of the structural equation modeling analysis are illustrated in Figure 3 and Table 4 as follow:

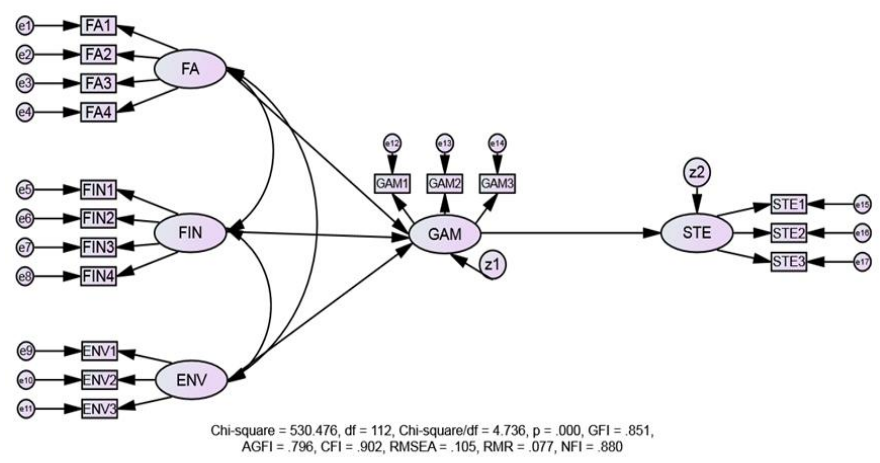

Figure 3. Hypothesized SEM model

Table 4. Comparison of goodness-of-fit measures between hypothesized SEM model and CFA model

\begin{tabular}{lll}
\hline \multicolumn{1}{c}{ Goodness of fit index } & $\begin{array}{r}\text { CFA } \\
\text { model }\end{array}$ & $\begin{array}{c}\text { Hypothesized } \\
\text { SEM model }\end{array}$ \\
\hline Chi-square & $p=0.000$ & $p=0.000$ \\
\hline $\begin{array}{l}\text { Absolute fit measures } \\
\text { GFI }\end{array}$ & 0.904 & 0.851
\end{tabular}


Table 4, cont.

\begin{tabular}{lll} 
RMSEA & 0.080 & 0.105 \\
RMR & 0.063 & 0.077 \\
Normed Chi-square & 3.180 & 4.736 \\
\hline Incremental fit indices & & \\
NFI & 0.925 & 0.880 \\
CFI & 0.947 & 0.902 \\
RFI & 0.902 & 0.854 \\
\hline Parsimony fit indices & & \\
AGFI & 0.859 & 0.796 \\
PNFI & 0.708 & 0.725 \\
\hline
\end{tabular}

Table 4 illustrates the overall fit statistics from testing the hypothesized model. The chi-square is 530.476 with 112 degree of freedom $(p<0.05)$, and the normed chi-square is 4.736 . The model CFI is .902 with RMSEA of .105. All of these measures are within an acceptable range that would be associated with good fit. The overall model fit changed a little from the CFA model.

Based on the residuals and modification indices information obtained from the hypothesized SEM model, we reanalyze the model by allowing covary between the errors of estimation. Hence, the model was re-estimated. The model fit statistics are shown in Figure 4 and Table 5.

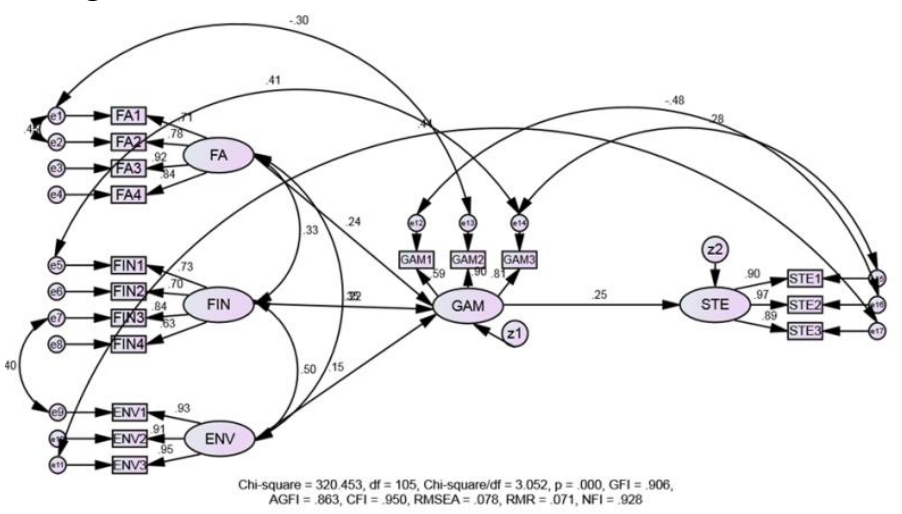

Figure 4. Revised SEM model

Table 5. Comparison of goodness-of-fit measures between hypothesized and revised SEM model

\begin{tabular}{lll}
\hline \multicolumn{1}{c}{ Goodness of fit index } & $\begin{array}{c}\text { Hypothesized } \\
\text { SEM model }\end{array}$ & $\begin{array}{c}\text { Revised } \\
\text { SEM model }\end{array}$ \\
\hline Chi-square & $p=0.000$ & $p=0.000$ \\
\hline Absolute fit measures & & \\
GFI & 0.851 & 0.906 \\
RMSEA & 0.105 & 0.078 \\
RMR & 0.077 & 0.071 \\
Normed Chi-square & 4.736 & 3.052 \\
\hline Incremental fit indices & & \\
NFI & 0.880 & 0.928 \\
CFI & 0.902 & 0.950 \\
RFI & 0.854 & 0.906 \\
\hline Parsimony fit indices & & \\
AGFI & 0.796 & 0.863 \\
PNFI & 0.725 & 0.716 \\
\hline
\end{tabular}

According to the information shown in Table 5, the chi-square is 320.453 with 105 degree of freedom ( $\mathrm{p}<0.05)$, and the normed chi-square is 3.052 . The model CFI is .950 and the RMSEA of 0.078. All of these measures are within an acceptable range suggesting that the model provides overall good fit.

Figure 4 illustrates relationship between each variable. Friend influence is the most important factor affecting game addiction among undergraduate students. Family relationship and social environment are ranked the second and third respectively. In addition, game addiction has a positive impact on stealing behavior of undergraduate students. It also plays an intermediate role in the relation between family relationship, friend influence, social environment and stealing behavior.

\section{DISCUSSION AND CONCLUSION}

According to the research findings, friend influence is the most important factor affecting game addiction among undergraduate students. This was consistent with the study of Chutchawarut (2009). University's executives should place important on the group influence. Extracurricular activities should be provided adequately in order to get them back to the school. In addition, providing knowledge on the impact of game addiction should be conducted through classroom activity as well as public relations. We also found that poor family relation is also the factor that has positive impact on game addiction. This supported the finding of Kolkijkovin et al. (2009). Activities among family members should be held in the regular basis so the children may feel warm and happy with their families. Social environment is another important factor. This finding is consistent with Charoenwanich (2014) and Chutchawarut (2009). The research found that game addiction could lead to stealing behavior among undergraduate students which supported the finding of Kulsiripunyo (2015). Hence, training and knowledge on criminal law should be provided in school so the students will concern about law violation.

\section{REFERENCES}

Charoenwanich, S. 2014. Game addiction behaviors: Impacts and preventions. Thai Science and Technology Journal 22(6): 871-879.

Chutchawarut, P. 2009. Factors related with game addition among teenagers. Phayao: Boromarajonnani College of Nursing, Phayao.

Kiatpojananan, K. 2010. The effect of using a group process on modification of computer game addicted behavior of prima- 
ry school students, North Sanklang School, San Kamphaeng district, Chiang Mai province. (Unpublished master's thesis), Chiang Mai University, Thailand.

Kolkijkovin, V. 2009. Computer game addiction: Risk and protective factors in students in Dusit District, Bangkok. Vajira Medical Journal 59(3): 1-13.

Kulsiripunyo, J. 2015. Game addiction behavior and stealing offence among teenagers: A case study of Sattaheeb, Chonburi. Nakhon Phanom University Journal 5(3): 16-23. 